\title{
Study of Hybrid PV-Wind Energy System to Isolated Micro-grid
}

\author{
Samir M. Dawoud ${ }^{*}$, Xiangning Lin \\ ${ }^{1,2}$ School of Electrical and Electronics Engineering, Huazhong University of Science and Technology, \\ Wuhan 430074, Hubei, China \\ ${ }^{1}$ Department of Electrical Power and Machines Engineering, Tanta University, Egypt \\ ${ }^{*}$ Corresponding author, e-mail: engsamirdawoud@yahoo.com
}

\begin{abstract}
The optimal sizing of the isolated hybrid microgrid using an optimization technique was proposed. The hybrid system features WT, PVand conversion systems wereused to feed the electrical load demand. A HOMER software was used to model system performance during a time of one year, considering Sensitivity variations in both the availability of renewable energy sources and variations in the load demand. The optimal solution was obtained with respect to decrease the cost of energy (COE) and the loss of power supply probability (LPSP) over a project lifetime of 25 years to improve the isolated operation of the microgrid. The aim of this study is to investigate an optimum combination of different energy systems which can supply electricity to a rural area in Egypt. The results show the COE for the optimal model was found $0.139 \$ / \mathrm{kWh}$ which is less than half of the alone PV or WT system.
\end{abstract}

Keywords: hybrid sources, battery storage, COE, LPSP, HOMER.

Copyright $@ 2015$ Institute of Advanced Engineering and Science. All rights reserved.

\section{Introduction}

The renewable energy sources (RES) have become the most solution of feeding rural areas in Egypt. This field has provided the researchers new research directions in RES. In comparison to traditional power systems, the hybrid power sources show the low prices and higher reliability for feeding load demand [1]. Some of The rural region in Egypt are still offgrid and have been still fed by the stand-alone diesel generators. This give main problem associated with diesel generator is the environmental pollution [2]. The environment pollution can be decreased when used The RES such as solar PV, WT generator, biomass etc. In addition as the fossil fuels are decreased over time, the RES have the possibility to take over them in coming years. The fossil fuel prices are also very much variation that in turn affects the energy prices. The work that present the feasibility study of using the isolated hybrid RES to reduce the consumption of diesel fuel in [3]. The optimal sizing of RES was presented a brief evaluation about the sizing proceduresestablished in the recent years [4]. In this paper, the authors have developed an isolated RES based hybrid system to feed an isolated area in Egypt. The model consists of WT sources, solar PV array,converter and batteries storage are considered. The hybrid power system is then evaluated for an isolated PV-WT-battery-converter combination and the COE with LPSP compared with other sensitivity analysis like the solar variation, the wind speed variation and the load demand variation. Previously different researchers have studied and calculated the isolated RES. A comparison between solar PV and wind energy for their reliability effect on micro-grid in Egypt is shown by [5]. In the isolated systems have been applied using diesel generators or more RES, but due to the increasing development of WT and PV sources, and diesel have high costs and high environmental pollution, these traditional systems are being modernized so as to combine more renewable energy technologies $[6,7]$.

The design and operation of hybrid sources by optimization software techniques are driven by the requirement to overcome the convolution of decision making in the presence of large variability of RES, variable energy load requirement profile, cost characteristics and different performance of equipment. The hybrid energy systems evaluation has been described using optimization software tools, different performance schemes and techniques [8, 9]. The methodology suggested a dynamic model to calculate the optimal operating strategy for a wind turbine with diesel and battery storage system during one day [10]. In Reference [11] the 
authors have used the optimal design of WT with diesel and battery storage system based on the structure of trade-offs shapes. So that for dispatch strategies the economics of charging batteries storages with diesel power are shown comparing with alternative models. The authors in reference [12] suggest a non-linear constrained system to get the optimal combination of the model that contains hydro, solar PV, WT, diesel and batteries storages using an iterative method. The best model is chosen from several combinations are compared together. The optimal sizing scheme for an isolated grid with diesel is existing in Reference [13] and [14]. The optimization technique based on GA to choice the optimal WT, PV rated power, battery storage nominal capacity, and inverter rating. The advantage of using renewables energies compared to a standalone diesel system are then measured. Though, in both works, the diesel systems are invalid and the resize is not estimated for an economic solutionin Reference [15] without using the diesel as a backup unit. In Reference [16] the authors have used a multi-objective evolutionary algorithm to decrease the $\mathrm{co} 2$ emissions and the COE. Other recent works the hybrid optimization model for electric renewable is widely used [17]. On the other hand this is tool does not optimize the scheme automatically of the model, being necessary to resize of the components values. Other works have immersed on mixed-integer LP formulations to improve micro-grid operations. The optimal planning of hybrid energy systems is introduced in Reference [18]. My main goal of this study the effects of adding hybrid solar PV and WT systems to the micro-grid to improve the isolated operation of the micro grid. HOMER software is used to optimize the cost analysis of PV-wind- battery hybrid power system for rural place in Egypt considering the LPSP which is of great significance and can be regarded as an improvement combined with the previous works. The other thing of the paper is organized as follows. Section 2 describes the Methodology of this work, Results and Discussion in section 3, The sensitivity analysis in section 4 and the conclusions in section 5 .

\section{Methodology}

HOMER simulates the operation of a model by making energy balance calculations for every hour in one year. HOMER compares the electrical and thermal load demand in the hour to the electric energy that the model can feed in that hour, and calculates the flows of electrical energy to and from each component of the system. For models that include battery storages, HOMER also decides for each hour how to work the generators and whether to charge or discharge the battery storage.HOMER performs these energy balance calculations for each model configuration that you want to consider. It then determines whether a configuration is feasible, i.e., whether it can meet the electric load demand under the conditions that you specify, and estimates the cost of installing and operating the model over the lifetime of the project. The system cost calculations account for costs such as initial, replacement, operation and maintenance (O\&M), fuel, and interest. HOMER compares the economics of a wide range of modeldesigns comprising variable numbers of renewable and nonrenewable energy sources. For equality, such comparisons must account for both initial capital and operating costs of each energy sources. In this study, two parameters including LPSP and COE were used to evaluate the performance of operation of the hybrid system.

The optimization problem is centered on the objective function with a set of unknown variables and a set of constraints. An optimization problem is defined as finding values of variables that minimize the objective function while satisfying the consideringconstraints. Here objective function is minimized cost and constraint is the LPSP. Let $\mathrm{C}_{\mathrm{wp}}$ is the total capital cost of solar PV, WT generator, storage battery and converters.

$$
\begin{aligned}
& \text { Min } C_{w p}=C_{P} N_{P}+C_{W} N_{W}+C_{b a} N_{b a}+C_{c o} N_{c o} \\
& \text { LPSP } \leq \text { LPSP Pe }_{\text {se }}
\end{aligned}
$$

Where, $N_{p}=0,1,2, \ldots, N_{b a}=0,1,2, \ldots, N_{W}=0,1,2, \ldots, N_{c o}=0,1,2, \ldots, C_{b a}$ is the cost of batteries, $C_{P}$ is the cost of PV, LPSP $P_{s e}$ is LPSP set according to the load requirement, $N_{b a}$ is the number of battery storage, $N_{W}$ is the number WT generators, $N_{P}$ is the number of PV panels in the $\mathrm{PV}$ array, $\mathrm{N}_{\mathrm{co}}$ is the number of converters. The total capital cost is given as follows [19].

$$
\mathrm{C}_{\mathrm{tot}}=\mathrm{C}_{\mathrm{wp}}+\mathrm{C}_{\mathrm{co}}
$$


Where, $\mathrm{C}_{\mathrm{co}}$ is the total constant costs including the cost of power conditioning equipment, design and installation etc.

\subsection{Renewable Resources}

The data for solar resource were founded from the NASA Surface Meteorology and Solar Energy website [20]. The specific location of Hurghada-Egypt is at a location of $27^{\circ} 15^{\prime} \mathrm{N}$ latitude and $33^{\circ} 48^{\prime} \mathrm{E}$ longitude.The annual average solar radiation of this Hurghada-Egypt is $6.1 \mathrm{kWh} / \mathrm{m}^{2} / \mathrm{d}$ as shown in Figure 1. The actual wind speed is obtained for Hurghada from [21]. The scaled annual average speed is $6.65 \mathrm{~m} / \mathrm{s}$ as shown in Figure 2.

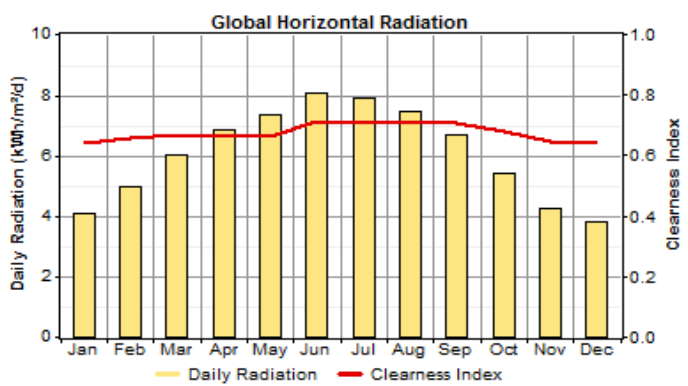

Figure 1. The annual solar radiation

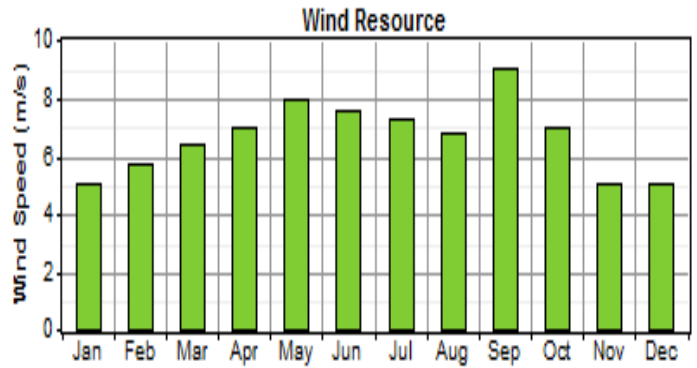

Figure 2. The annual wind speed

\subsection{System Components}

The proposed hybrid systems consist of PV panels, WT and other system components such as batteries and converters as shown in Figure 3. Maintenance and replacement costs of the hybrid renewable energy system can be reduced when renewable resources are adequately explored [22]. The capital cost of a hybrid system is usually high; hence, long-lasting, reliable, and cost-effective systems are needed to meet the complete project life. Assumptions regarding components pricing and sizing as adopted in the proposed hybrid system, are expressed as follows:

(a) The capital cost and replacement cost of $1 \mathrm{Wof} P V$ array were taken as $\$ 2.5$ and $\$ 2.2$ respectively. The lifetime of PV arrays was taken as 20 years and no tracking system was considered. The de-rating factorwas assumed as $85 \%$, that accounts for losses due to temperature effects and dirts on the PV modules surface, and the ground reflection of the modules were taken as $20 \%$. Different sizes of PV arrays were considered to get the optimal size.

(b) A Generic model WT with rated capacity of $10 \mathrm{~kW}$ is considered. The initial cost of one unit is taken as $\$ 9100$. The replacement and O\&M costs were assumed as $\$ 8500$ and $\$ 100 /$ year respectively. In order to get an optimal size, different sizes of WT options were analyzed. The lifetime of the WT was considered as 25 years.

(c) A bi-directional converter is added to maintain the flow of energy between the alternating current and direct current components. It function as a rectifier when it converts AC to DC and as inverter on the other way round. The capital and replacement cost of the converter used in this paper were taken as $\$ 350 / \mathrm{kW}$ and $\$ 350 / \mathrm{kW}$ respectively. The O\&M cost is assumed as $\$ 10$ /year. The efficiency of the converter is assumed to be $90 \%$ andwhen used as a rectifier is $85 \%$ while the lifetime was taken as 15 years. Different sizes of converters were considered during the analysis.

(d) Surrette 6CS25P type battery with rated $6 \mathrm{~V}$ nominal voltage. The capacity is considered in this study $1156 \mathrm{Ah}(6.94 \mathrm{kWh})$. The initial cost of one unit is $\$ 400$. The replacement and O\&M costs were assumed as $\$ 400$ and $\$ 10 /$ year respectively. In order to find an optimal solution the battery bank was assumed to contain the number of batteries string. Each battery string contains 3 batteries.

(e) Hourly load of $10 \%$ is considered in the simulation and has operating reserve that accounts for sudden spikes in the system, $20 \%$ reserve is considered for the PV panels output due to its inherent dependence on solar irradiance, $20 \%$ reserve is considered for the WT 
generator output due to its inherent dependence on wind speed variations and hence unpredictable output.

(h) Maximum hourly load of $7 \%$ is considered as the capacity shortage factor; this shows the amount of time to the system will not be able to meet the load requirement including its reserves.

(f) The Hourly electrical load demand has been given as an input to configuration to HOMER and then it generates AC primary load annual profile. The scaled annual average load is $850 \mathrm{kWh} /$ day. As the daily load profile, there is a peak of $115 \mathrm{~kW}$. The AC primary load daily profile is shown in Figure 4.

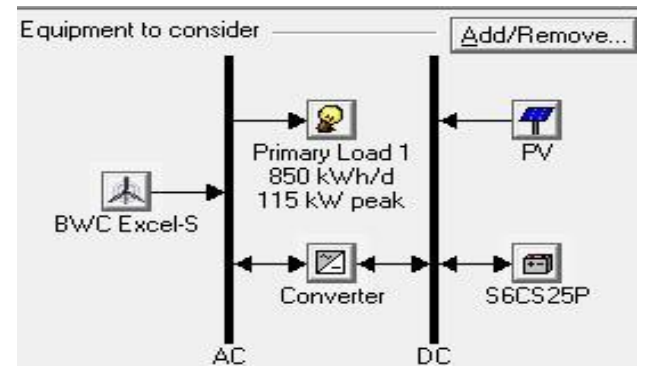

Figure 3. The model of hybrid renewable energy system setup

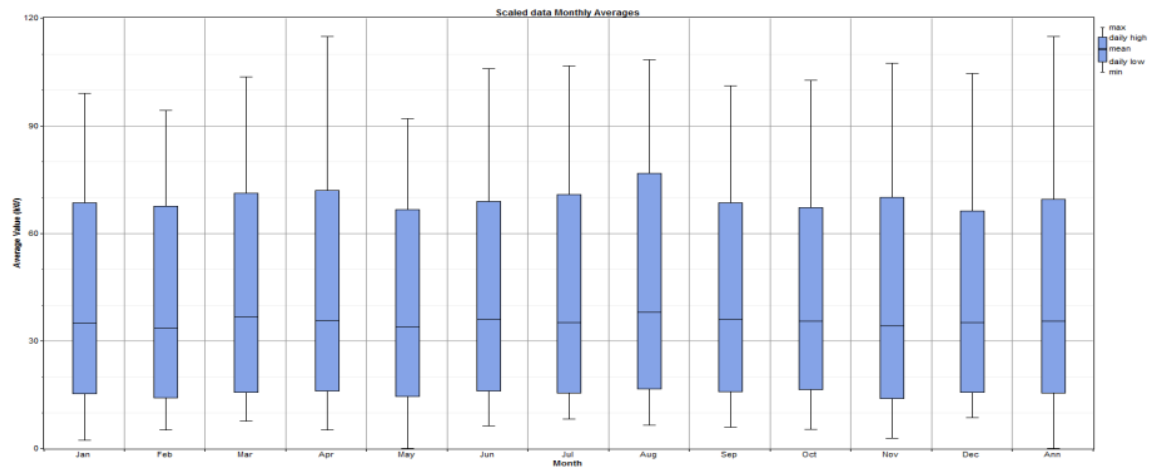

Figure 4. AC primary load daily profile

\subsection{Loss of Power Supply Probability (LPSP)}

The LPSP is a measurable probability of the load being fed by the supply. The LPSP = 0 mean the load will be supplied and this occur when the energy generated by RES plus the energy supplied by the battery storage is greater than the energy required by the load requirement. The LPSP $=1$ mean the load is never fed by the sources.

\subsubsection{Calculation of Solar Energy}

A photovoltaic system employs solar panels composed of a number of solar cells in series/parallel to generate power from solar PV, while light intensity is affected by shadows, clouds and other factors, which presents a certain level of randomness. The output power of PV panels $P_{P}(t)$ at any time can be calculated as:

$$
P_{P}(t)=Y_{p} f_{p} \frac{G_{T r}}{G_{T r, S T C}}
$$

Where, $f_{p}$ is the PV derating factor. $Y_{p}$ is the rated capacity of the solar PV array $(k W)$. $G_{T r}$ is the solar radiation incident on the solar $\mathrm{PV}$ array $\left(\mathrm{kW} / \mathrm{m}^{2}\right) . \mathrm{G}_{\mathrm{Tr}, \mathrm{STC}}$ is the solar radiation incident at standard conditions $\left(1 \mathrm{~kW} / \mathrm{m}^{2}\right)$. 


\subsubsection{Calculation of Wind Turbine Energy}

The power curve of a WT gives the electrical power output as a function of wind velocity. The characteristic curve from the generic WT considered in this work is depicted in Figure 5 More specifically, the energy $(\mathrm{kWh})$ produced by a WT in time step $\mathrm{t}$ is given by:

$$
\mathrm{P}_{\mathrm{W}}(\mathrm{t})=\left\{\begin{array}{lr}
0, & \mathrm{~s} \leq \mathrm{s}_{\text {in }}, \mathrm{s}>\mathrm{s}_{\text {cout }} \\
\mathrm{A}+\mathrm{Bs}+\mathrm{Cs}^{2}, & \mathrm{~V}_{\text {in }}<s \leq \mathrm{s}_{\mathrm{r}} \\
\mathrm{P}_{\mathrm{ra}}, & \mathrm{s}_{\mathrm{r}}<s \leq \mathrm{s}_{\text {cout }}
\end{array}\right.
$$

Where, $A, B, C$ are the wind power characteristic curve parameters, slightly different for different wind turbines; $P_{r a}$ is the WT rated power; $s_{i n}, s_{r}, s_{\text {cout }}$ are the cut-in, rated and cut-out wind speed and the values of these speeds is $4 \mathrm{~m} / \mathrm{s}, 14 \mathrm{~m} / \mathrm{s}, 25 \mathrm{~m} / \mathrm{s}$ respectively. The electrical energy generated is limited by the range of operation of the WT, between the cut-in and cut-out wind speed. Considering the hub installation height of the WT is $30 \mathrm{~m}$.

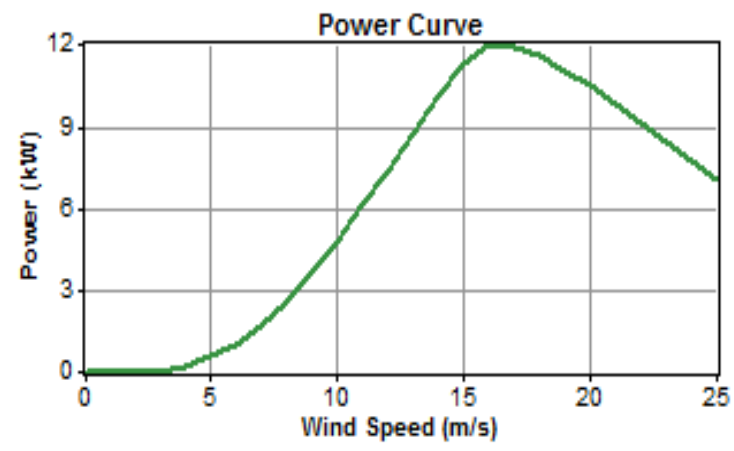

Figure 5. Output curve of wind generator active power

\subsubsection{Calculation of Energy Storage Battery Output Model}

The batteries are regarded as energy storage elements. When the distributed power generation within micro-grid is sufficient, the batteries recharge; when power generation is lacking, the batteries discharge, thus playing a very essential role in the operation of isolated micro-grid. The batteries are used to store the excess energy generated by the RES and feed the energy during the low generation period. The power input to the battery bank is calculated as:

$$
\Delta \mathrm{P}(\mathrm{t})=\mathrm{P}_{\mathrm{to}}(\mathrm{t})-\mathrm{P}_{\mathrm{lo}}(\mathrm{t})
$$

Where, $P_{t o}(t)$ is the total power generated by the RES at hour $t, P_{10}(t)=P_{\text {dem }}(t) / \eta_{b i}$, where, $P_{\text {dem }}(t)$ is the power required by the electrical load demand at hour $t, \eta_{b i}$ is the inverter efficiency. For the discharging process, $(\Delta \mathrm{P}(\mathrm{t})<0)$ of the battery bank, for the charging process, $(\Delta \mathrm{P}(\mathrm{t})>0$ ) of the battery bank and the state of charge (SOC)can be calculated as:

$$
\mathrm{P}_{\mathrm{ba}}(\mathrm{t}+1)=\mathrm{P}_{\mathrm{ba}}(\mathrm{t})+\left(\frac{\Delta \mathrm{P}(\mathrm{t})}{\mathrm{v}_{\mathrm{b}}}\right) * \Delta \mathrm{t} * \mu_{\mathrm{b}}
$$

Where, $\mu_{\mathrm{b}}$ is equal the round-trip efficiency in the charging process and the value $100 \%$ in the discharging process, $v_{b}$ is the $\mathrm{DC}$ bus voltage, and $\Delta t$ is the time step which is generally one hour. The total power generated by the RE resources at hour $t$ is given by the following equation.

$$
\mathrm{P}_{\mathrm{to}}(\mathrm{t})=\sum_{\mathrm{P}=1}^{\mathrm{S}_{\mathrm{n}}} \mathrm{P}_{\mathrm{PV}}(\mathrm{t})+\sum_{\mathrm{W}=1}^{\mathrm{W}_{\mathrm{m}}} \mathrm{P}_{\mathrm{W}}(\mathrm{t})
$$

Where, $S_{n}$ and $W_{m}$ are the total numbers of solar PV panels and WT generator respectively. 


\subsubsection{Loss of Power Supply Probability}

The LPSP, which is defined in terms of the SOC, is the power reliability index of the system. LPSP can be defined as the long-term average fraction of the load that is not fed by the isolated power system. The SOC of the batteries at any time $t_{1}$ depends on the SOC in the previous time $t_{0}$ and the sequence of generated power and load demand levels in the time interval $t_{1}-t_{0}$. The SOC is used as a variable for the control of over discharge and overcharge. This is important to prevent batteries from shortening their life or even their destruction. In terms of the SOC, the LPSP can be defined as [19]:

$$
\text { LPSP }=P_{r}\left\{E_{b a, t} \leq E_{\text {bamin }} ; \text { for } t \leq T\right\}
$$

Where, $E_{b a, t}$ is the energy stored in batteries at any hour $t, E_{b a m i n}$ is the battery minimum allowable energy level. Let $\mathrm{E}_{\text {bamax }}$ is a battery nominal capacity with the value of the battery SOC as:

$$
\mathrm{E}_{\mathrm{ba} \min }=(1-\mathrm{DOD}) \mathrm{E}_{\mathrm{baMax}}
$$

Where, DOD is the depth of discharge equal 30 to $50 \%$.In the simulation, the sum of all energy sources must equal the sum of all sinks. The simulation period is one year and the time step is one hour. The load, WT energy and solar energy are assumed to be constant during a time step. The energy generated by the WT and solar PV array for hour $t, E_{\text {gen,t }}$, can be expressed as [19]:

$$
E_{\text {gen,t }}=N_{P} E_{P, t}+N_{W} E_{W, t}
$$

Where, $E_{P}$ is the energy generated by the PV array, $E_{W}$ is the energy generated by the WT generator.If the generated energy from the WT and PV array exceeds that of the load demand, the batteries will be charged with the round-trip efficiency:

$$
E_{b a, t}=E_{b a, t-1}(1-\sigma)+\left[E_{g e n, t}-E_{L o, t} / \mu_{i n}\right] \mu_{b a}
$$

Where, $E_{b a, t}$ is the energy stored in the batteries in one hour $t, E_{b a, t-1}$ is the energy stored in the batteries in the previous hour, $E_{L o, t}$ is the load demand in time $t, \mu_{\mathrm{ba}}$ is the round-trip efficiency of the batteries, $\mu_{\text {in }}$ is the inverter efficiency, $\sigma$ is the self-discharge rate per hour of the batteries. When the load demand is greater than the available energy generated, the batteries will be discharged by the amount that is needed to cover the deficit. This can be expressed as [23]:

$$
E_{b a, t}=E_{b a, t}(1-\sigma)-\left[E_{L o, t} / \mu_{i n}-E_{g e n, t}\right]
$$

When the available energy generated and stored in batteries is insufficient to supply the load demand for time $t$, that deficit called LPS for hour $t$ can be expressed as [23]:

$$
\mathrm{LPS}_{\mathrm{t}}=\mathrm{E}_{\mathrm{Lo}, \mathrm{t}}-\left[\mathrm{E}_{\text {gen }, \mathrm{t}}+\mathrm{E}_{\mathrm{ba}, \mathrm{t}-1}-\mathrm{E}_{\mathrm{ba} \text { Min }}\right] \mu_{\mathrm{in}}
$$

The LPSP for a considered period T is the ratio of all LPS values for that period to the sum of the load demand in the same period, as defined by [23]:

$$
\text { LPSP }=\frac{\sum_{\mathrm{t}=1}^{\mathrm{T}} \mathrm{LPS}_{\mathrm{t}}}{\sum_{\mathrm{t}=1}^{\mathrm{T}} \mathrm{E}_{\mathrm{Lo}, \mathrm{t}}}
$$

\section{Results and Discussion}

With the simulations conducted by HOMER, Figure 6 shows the hybrid system consisting of WT, solar PV, battery storage and converter with different combinations including PV-battery-converter, WT-battery-converter and WT-PV-battery-converter. The optimal hybrid system (WT-PV-battery-converter) has the lowest COE of the system which value is 0.138 $\$ / \mathrm{kWh}$ with the loss of load expected is $20915 \mathrm{kWh} /$ year. The COE for WT-battery-converter is 
$0.204 \$ / \mathrm{kWh}$ with the loss of load expected is $21242 \mathrm{kWh} / \mathrm{year}$. The COE for PV-batteryconverter is $0.285 \$ / \mathrm{kWh}$ with the loss of load expected is $21091 \mathrm{kWh} /$ year. From the result shown the COE and loss of load expected are decreased with the model contains solar PV with WT generator. The results are presented show the optimal model of solar PV with WT reduce the COE and loss of load expected of the micro-grid.

According to the HOMER simulation results, for the optimal system the total net present cost of the micro-grid based on the hybrid system configuration is \$520456 and COE is $0.138 \$ / \mathrm{kWh}$. This project requires the initial capital cost of $\$ 395500$ and operating cost $\$ 9775$ for implementation. Figure 7 illustrates how the costs are distributed among different components of the system.

\begin{tabular}{|c|c|c|c|c|c|c|c|c|c|c|}
\hline \multicolumn{11}{|c|}{ Sensitivity Results Optimization Results } \\
\hline \multicolumn{11}{|l|}{ Sensitivity variables } \\
\hline Primary Load 1 (kWh/c & 850 & $\nabla$ Glo & \multicolumn{3}{|c|}{ Global Solar $\left(k W / h / \mathrm{m}^{2} / d\right) 6.08$} & \multicolumn{3}{|c|}{$\checkmark$ Wind Speed $(\mathrm{m} / \mathrm{s}) 6.65 \quad$} & & \\
\hline \multicolumn{11}{|c|}{ Double click on a system below for simulation results. } \\
\hline 甲从国园 $\begin{array}{c}P V \\
(\mathrm{~kW})\end{array}$ & $\mathrm{XLS}$ & S6CS25P & $\begin{array}{l}\text { Conv. } \\
(\mathrm{kW})\end{array}$ & \begin{tabular}{|l|} 
Disp. \\
Strgy
\end{tabular} & $\begin{array}{l}\text { Initial } \\
\text { Capital }\end{array}$ & $\begin{array}{l}\text { Operating } \\
\text { Cost }(\$ / y r)\end{array}$ & $\begin{array}{l}\text { Total } \\
\text { NPC }\end{array}$ & $\begin{array}{c}\mathrm{COE} \\
(\mathrm{s} / \mathrm{kWh})\end{array}$ & $\begin{array}{l}\text { Ren. } \\
\text { Frac. }\end{array}$ & $\begin{array}{l}\text { Capacity } \\
\text { Shortage }\end{array}$ \\
\hline 甲A国目 & 20 & 240 & 50 & $C \mathrm{C}$ & $\$ 395,500$ & 9,775 & $\$ 520,456$ & 0.138 & 1.00 & 0.07 \\
\hline 从国 & 20 & 600 & 200 & $\mathrm{CC}$ & $\$ 492,000$ & 21,300 & $\$ 764,292$ & 0.204 & 1.00 & 0.07 \\
\hline 200 & & 600 & 100 & $\mathrm{CC}$ & $\$ 775,000$ & 22,605 & $\$ 1,063,962$ & 0.285 & 1.00 & 0.07 \\
\hline
\end{tabular}

Figure 6. Optimization result for the WT-PV-battery-converter model with HOMER in the project

In the optimal hybrid system, the solar PV contributes $12 \%$ of the annual electricity production and the WT generator $88 \%$ of the annual electricity production as shown in Fig. 8. The optimal hybrid system is decreased the loss of load expected from $21242 \mathrm{kWh} /$ year to $20915 \mathrm{kWh} /$ year and decreased the COE from $0.285 \$ / \mathrm{kWh}$ to $0.138 \$ / \mathrm{kWh}$. From this result the advantage of the optimal model that contains solar PV with WT generator states as follows:

1) Decrease the COE.

2) Decrease the LPSP and the environmental emissions.

3) Make the fuel consumption equal zero.

4) Feed the rural region with renewable energy sources.

5) The RF equal $100 \%$

In the optimal system give a good result because the solar PV and WT system complementarily supply the required power. During sunny hours of the day, solar PV model feeds power and on cold days, the WT generator is in the position to feed power for the electrical load. The battery storage are designed in order to be able to store excess power from both the solar PV and WT hybrid system during the time of high solarradiation and wind speed. The electrical stored energy was used to support the load during the hours when the output of $R E$ sources is not sufficient to feed the load. When the power generation from RES is not sufficient to cover the electrical load demand and the battery storage has reached its minimum, the decision of SOC here disconnect some loads this mean Loss of power supply (LPS) will occur.

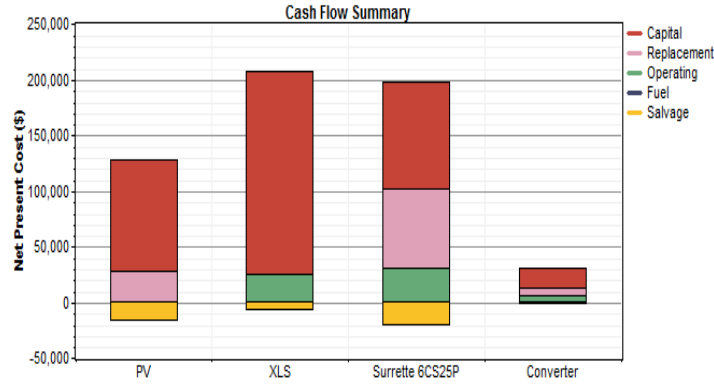

Figure 7. Cost Summery of the project

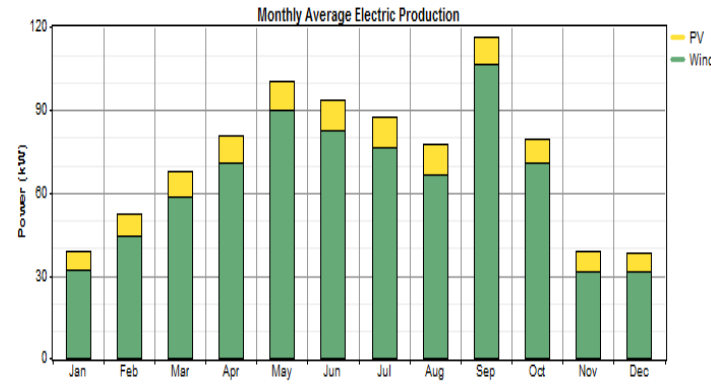

Figure 8. Monthly electricity production for PVWT system 


\section{Sensitivity Analysis}

The sensitivity analysis make for the variations in the electrical load demand with values 600,850 and 1000 ( $\mathrm{kwh} /$ day), the variation in the solar radiationwith values 5, 6.1, $10\left(\mathrm{kwh} / \mathrm{m}^{2} / \mathrm{d}\right)$ and the variation in wind speed with values $5,6.65$ and $8(\mathrm{~m} / \mathrm{s})$.HOMER optimization algorithm finds the optimum hybrid configuration based on the user inputs. But there may be uncertainties in these inputs especially inthe solar radiation data, the wind speed data and Load demand data. The simulations are done by considering the uncertainties of the annual average wind speed, load demand and solar radiation.

\subsection{Optimal System Type}

The optimal system type for variations in annual average solar radiation, load demand and wind speed around the base values $\left(6.08 \mathrm{kwh} / \mathrm{m}^{2} /\right.$ day, $1000 \mathrm{kwh} /$ day, $\left.6.65 \mathrm{~m} / \mathrm{s}\right)$. Figure 910 show that Wind/PV/Battery hybrid configuration is the optimal system type for majority of the variations considered in annual average solar radiation and load demand with wind speed 5 and $6.65 \mathrm{~m} / \mathrm{s}$ respectively. Therefore Wind/PV/ Battery hybrid configuration is selected as the optimal configuration. Figure 11 shows that Wind / PV /Battery hybrid configuration is the optimal system type for majority of the variations considered in annual average solar radiation and load demand with wind speed $8 \mathrm{~m} / \mathrm{s}$, except the area colored in green. Therefore Wind/PV/ Battery hybrid configuration is selected as the optimal configuration. The optimal system for the green area is taken wind/battery because the high wind speed. Figure (9-11) show was variation of wind speed from 5 to $8 \mathrm{~m} / \mathrm{s}$ the optimal system change in some region from wind/PV/battery to wind/battery this because high wind speed and wind power is less initial capital cost than the PV power.

\subsection{Effect of Wind Speed, Load Demand and Solar Radation on the COE}

Figure 13 and 14 illustrates the variation of the COE for changes in the annual average wind speed and solar radiation around the nominal values. As shown in these Figure 13 and 14, when the wind speed and solar radiation increases, the COE decreases. This is due to the increase in the renewable fraction. The COE decreased for the variations in the wind speed in the range of $5-8(\mathrm{~m} / \mathrm{s})$ is about $0.14 \$ / \mathrm{kWh}$. But for the variations in solar radiation within the range of $5-10 \mathrm{kWh} / \mathrm{m}^{2} /$ day, the change in COE is $0.02 \$ / \mathrm{kWh}$. The renewable fraction for all variations remains constant with value 1 as shown in Figures $(12,15)$.

It can be observed from the Figure 9-11 that the optimal system fed all load variations (600, 850 and $1000 \mathrm{kWh} /$ day). The capacity shortage decreased with wind speed increase for Figure 12 from $0.07 \%$ to $0.068 \%$ for variation of the wind speed from 5 to $8 \mathrm{~m} / \mathrm{s}$ and this improve the reliability of isolated micro-grid. The capacity shortage decreased with solar radiation increase for Figure 14 from $0.068 \%$ to $0.067 \%$ for variation the solar radiation from 5 to $10 \mathrm{kWh} / \mathrm{m}^{2} /$ day and this improve the reliability of isolated micro-grid.

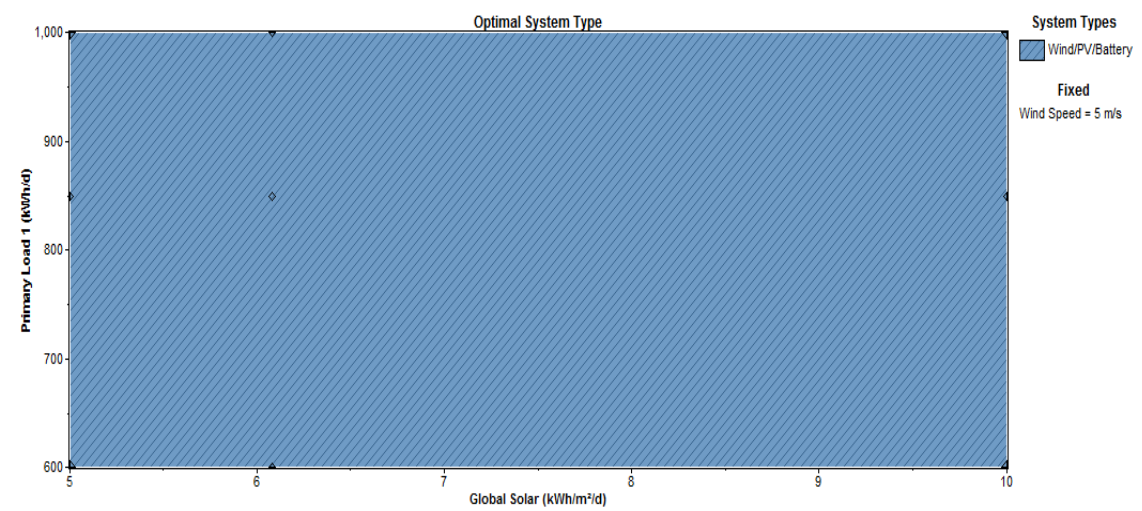

Figure 9. Optimum system for different average solar radiation and load varation with constant wind speed $(5 \mathrm{~m} / \mathrm{s})$ 


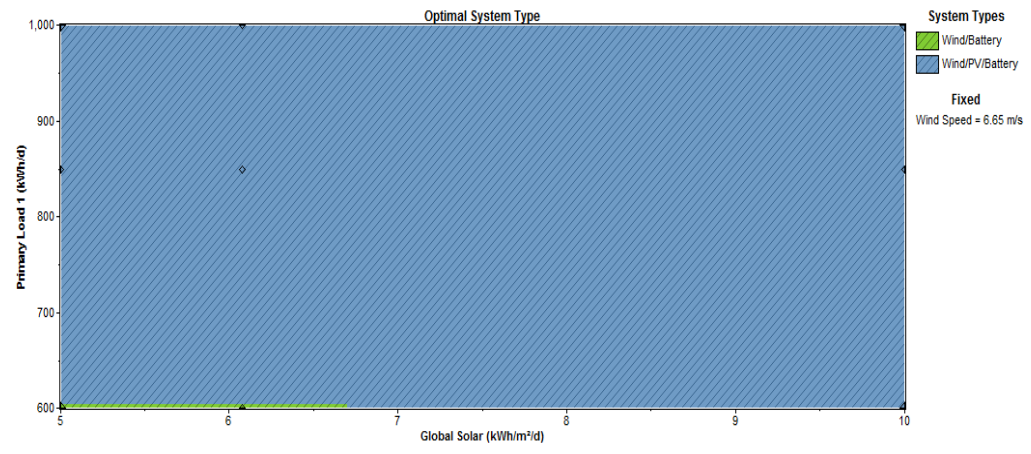

Figure 10. Optimum system for different average solar radiation and load varation with constant wind speed $(6.65 \mathrm{~m} / \mathrm{s})$

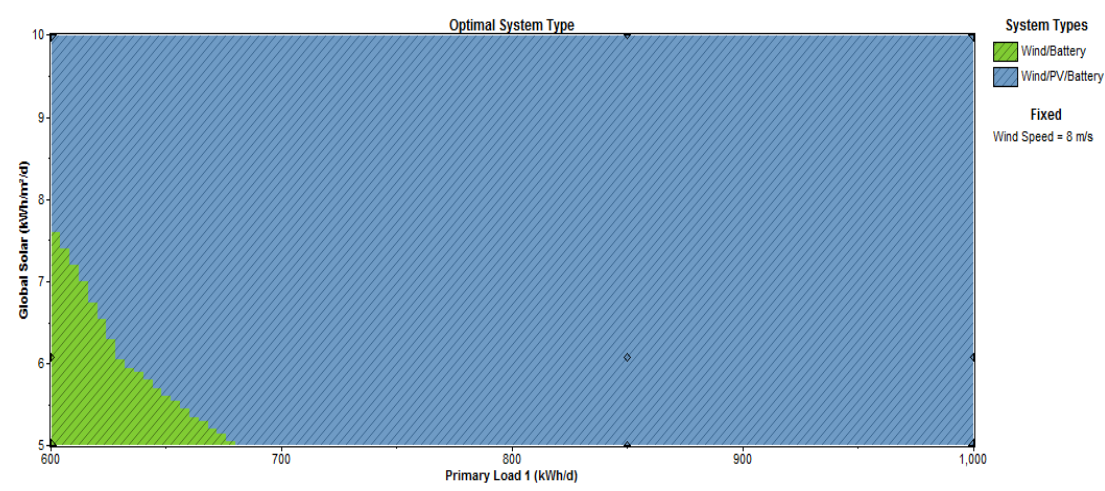

Figure 11. Optimum system for different average solar radiation and load varation with constant wind speed $(8 \mathrm{~m} / \mathrm{s})$

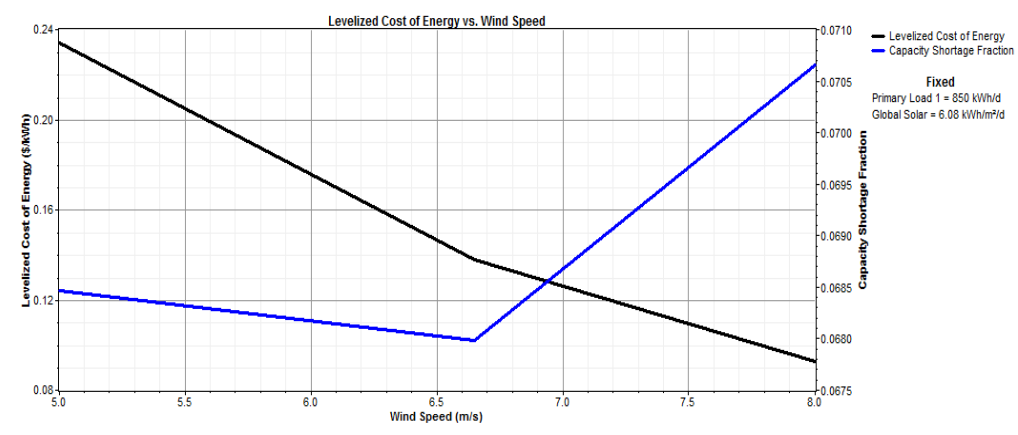

Figure 12. Variation of COE and capacity shortage fraction for different annual wind speed

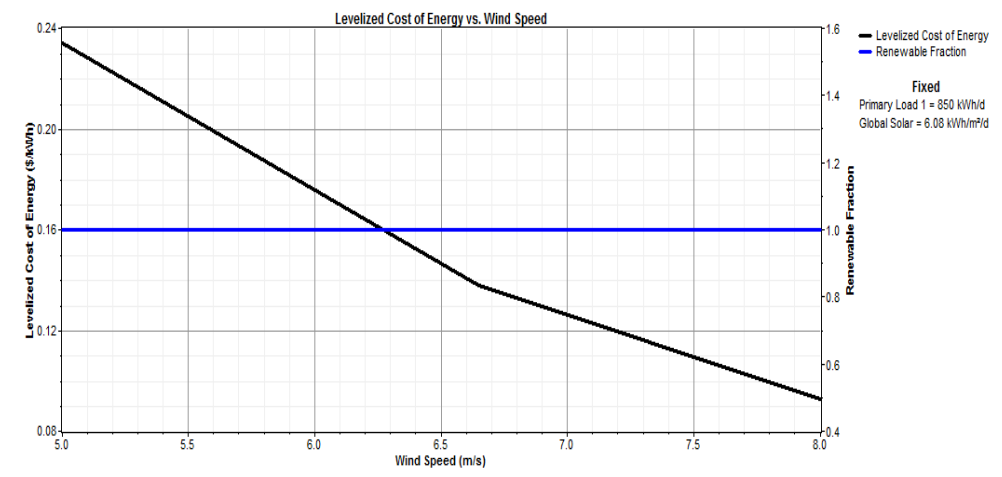

Figure 13. Variation of COE and RF for different annual wind speed 


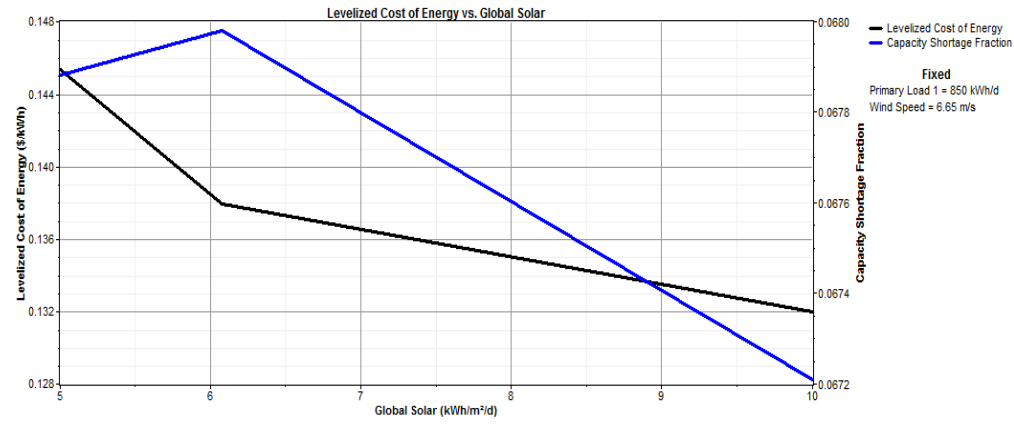

Figure 14. Variation of COE and capacity shortage fraction for different annual solar radation

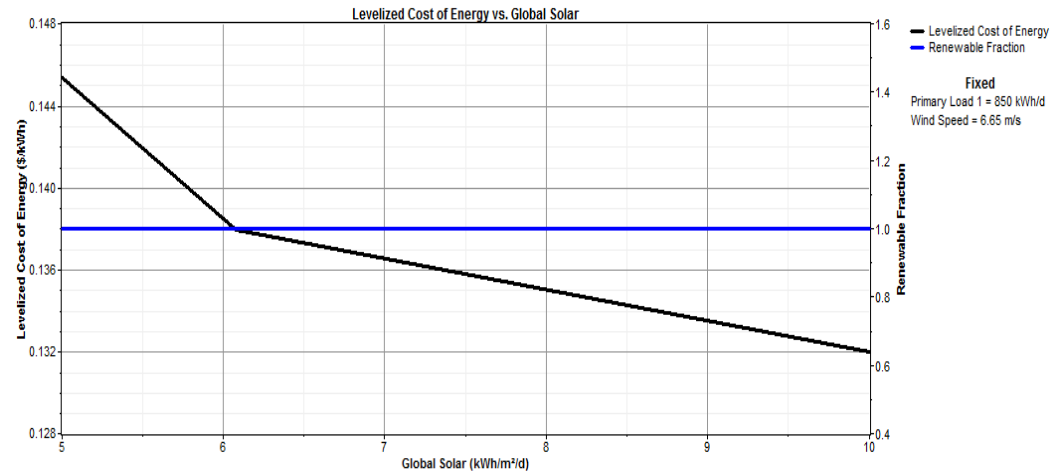

Figure 15. Variation of COE and RF for different annul solar radation

\section{Conclusion}

The effect of adding hybrid solar PV and WT systems to the micro-grid to improve the operation of the isolated micro grid has been studied in this paper. This study performed the LPSP based on adding the hybrid solar PV and WT to the isolated micro grid. The HRS used to reduce the dependency on either conventional energy sources. this technology is the need of the future to avoid energy crisis situation. Load can be feed in an optimal way by using RES. In this approach all of the economic costs include capital, replacement cost, O\&M cost and etc. have been considered. Homer software has been used to solve the optimization problemsBecause of variations of the system constraints. The optimal system that contains the solar PV with WT generator are more reliable and reduce the COE compared to other systems that contains alone solar PV or alone WT generation and have minimum LPSP. The all hybrid renewable system significantly reduces the environmental emissions that use hybrid renewable energy for feed the rural region. The effect of the changes in the annual average wind speed and solar radiation on the COE of this system is analyzed. Simulation results showed 0.14 $\$ / \mathrm{kWh}$ increase in the COE for the variations in the annual average wind speed from 8 to $5 \mathrm{~m} / \mathrm{s}$. The capacity shortage decreased with wind speed increase from 5 to $8 \mathrm{~m} / \mathrm{s}$ with $0.2 \%$. The capacity shortage decreased with solar radiation increase from 5 to $10 \mathrm{kWh} / \mathrm{m} 2 /$ day with $0.1 \%$ and this improve the reliability of isolated micro-grid.

\section{Acknowledgements}

This work was supported in part by the National Natural Science Foundation of China (51277110), and in part by the National Key Basic Research Program of China (973 Program) (2012CB215100), and in part by the Research Fund for the Doctoral Program of Higher Education of China (20110142110055), and in part by Natural Science Foundation of Hubei Province (2012FFA075). 


\section{References}

[1] Y Li, X Chen, J Xiao, X Wei. Optimal configuration for distributed generations in micro-grid system considering diesel as the main control source. In Advanced Mechatronic Systems (ICAMechS), 2014 International Conference. 2014: 552-556.

[2] G Dalton, D Lockington, T Baldock. Feasibility analysis of stand-alone renewable energy supply options for a large hotel. Renewable energy. 2008; 33: 1475-1490.

[3] SM Dawoud, XN Lin, JW Sun, MI Okba, MS Khalid, A Waqar. Feasibility Study of Isolated PV-Wind Hybrid System in Egypt. In Advanced Materials Research. 2015: 145-151.

[4] R Luna-Rubio, M Trejo-Perea, D Vargas-Vázquez, G Ríos-Moreno. Optimal sizing of renewable hybrids energy systems: A review of methodologies. Solar Energy. 2012; 86: 1077-1088.

[5] E Beshr. Comparative study of adding PV/wind energy systems to autonomus micro grid. In Electric Power and Energy Conversion Systems (EPECS), 2013 3rd International Conference. 2013: 1-6.

[6] Hunter R, Elliot G. Wind-diesel systems. Cambridge University Press. 1994.

[7] Lund sager P, Baring-Gould El. Isolated systems with wind power. In Wind power in power systems. John Wiley \& Sons. 2005: 299-329.

[8] Zhou W, Lou C, Li Z, Lu L, Yang H. Current status of research on optimum sizing of stand-alone hybrid solar-wind power generation systems. Appl Energy. 2010: 380-389.

[9] Bajpai P, Dash V. Hybrid renewable energy systems for power generation in stand-alone applications: a review. Renew Sustain Energy. 2012; 16: 2926-2939.

[10] Musgrove A. The optimization of hybrid energy conversion systems using the dynamic programming model RAPSODY. Int J Energy Res. 1988; 12: 447-457.

[11] Barley CD, Winn CB. Optimal dispatch strategy in remote hybrid power systems. Sol Energy. 1996; 58: $165-179$

[12] Ashok S. Optimized model for community-based. Renew Energy. 2007; 32: 1155-1164.

[13] Senjyu T, Hayashi D, Yona A, Urasaki N, Funabashi T. Optimal configuration of power generating systems in isolated island with renewable energy. Renew Energy. 2007; 32: 1917-1933.

[14] Vrettos EI, Papathanassiou SA. Operating policy and optimal sizing of a high penetration RES-BESS system for small isolated grids. IEEE Trans Energy Convers. 2011;26(3).

[15] Koutroulis E, Kolokotsa D, Potirakis A, Kalaitzakis K. Methodology for optimal sizing of stand-alone photovoltaic/wind-generator systems using genetic algorithms. Sol Energy. 2006; 80: 1072-1088.

[16] Dufo-Lopez R, Bernal-Agustín JL. Multi-objective design of PV-wind-diesel hydrogen-battery systems. Renew Energy. 2008; 33: 2559-2572.

[17] Hafez O, Bhattacharya K. Optimal planning and design of a renewable energy based supply system for micro grids. Renew Energy. 2012; 45: 7-15.

[18] Morais H, Kadar P, Faria P, Vale ZA, Khodr HM. Optimal scheduling of a renewable micro-grid in an isolated load area using mixed-integer linear programming. Renew Energy. 2010; 35(1): 151-156.

[19] VK Soni, R Khare. Optimal sizing of HRES for small sized institute using HOMER. in Electrical Energy Systems (ICEES), 2014 IEEE 2nd International Conference. 2014: 77-81.

[20] http://eosweb.larc.nasa.gov/sse/2015.

[21] Annual report "New and renewable Energy association of Egypt. 2014

[22] Haidar AM, John PN, Shawal M. Optimal configuration assessment ofrenewable energy in Malaysia. Renew Energy. 2011; 36(2): 881-888.

[23] I Sansa, R Villafafila, N Mrabet Bellaaj. Optimal sizing design of an isolated micro grid using loss of power supply probability. In Renewable Energy Congress (IREC), 2015 6th International. 2015: 1-7. 